\title{
Magola: visión ginocéntrica y empoderamiento de la mujer
}

Magola, creación de Adriana (Nani) Mosquera, ha sido calificada como una "heroína de la viñeta en Colombia". Su labor de portavoz en favor del empoderamiento y la defensa de los derechos humanos de la mujer le ha ganado reconocimiento internacional. Este artículo comenta la combinación de recursos textuales y gráficos para desconstruir, subvertir y revisar el texto patriarcal bíblico en Magola: La verdadera historia de Eva, y el empleo de un discurso ginocéntrico que apoya el empoderamiento de la mujer en los blogs Sobreviviendo en pareja y Mujer y caricaturista (El Espectador). Este análisis se basa en la discusión de Gerda Lerner en The Creation of Feminist Consciousness sobre los retos que ha debido sobrepasar la mujer creadora a lo largo de la historia y las estrategias de visión ginocrítica estudiadas por John Wilcox en Women Poets of Spain I860-I990: Toward a Gynocentric Vision.

Palabras clave: Nani, Magola, la Biblia, visión ginocéntrica, empoderamiento y derechos humanos de la mujer

Magola, the cartoon character created by Adriana (Nani) Mosquera, has been called "a hero of the Colombian comic." Her activism in favour of women's empowerment and human rights has brought her international renown. This article discusses the combination of image and text to deconstruct, subvert, and revise the patriarchal Biblical discourse in Magola: La verdadera historia de Eva, and the use of a gynocentric discourse that leads to the empowerment of women in her blogs, Sobreviviendo en pareja and Mujer y caricaturista (El Espectador). This analysis is informed by Gerda Lerner's discussion in The Creation of Feminist Consciousness of the challenges that creative women have encountered throughout history, and the gynocentric strategies described by John Wilcox in Women Poets of Spain I860-I990: Toward a Gynocentric Vision.

Keywords: Nani, Magola, the Bible, gynocentric vision, women's empowerment and human rights 
SOBRE LA AUTORA

Adriana (Nani) Mosquera es la creadora del personaje Magola. ${ }^{I}$ Nani es profesora honorífica de la cátedra de humor en la Universidad de Alcalá de Henares, donde radica desde 1998. Sus viñetas aparecen en periódicos y revistas en España, México, Argentina y los Estados Unidos. Su exitosa y prolífica trayectoria sobrepasa ya dos décadas. Es autora de I4 libros y de los blogs Sobreviviendo en pareja y Mujer y caricaturista, este último publicado semanalmente en El Espectador, uno de los periódicos de circulación nacional más importantes en Colombia.

Entre los artículos periodísticos que se han ocupado de su obra vale la pena destacar la nota "Heroínas de la viñeta en Colombia" de Magdalena Barrero. ${ }^{2}$ Los estudios académicos se centran en el contenido sociopolítico de las tiras de Nani (Carlos Alberto Villegas, Jeanette Uribe-Duncan), o en el humor gráfico de varios artistas desde una perspectiva feminista (Carolina Rodríguez Arévalo). Sin embargo, dichos estudios son limitados en cuanto a que las referencias a su obra hacen parte de análisis más amplios que incluyen varios autores.

El presente trabajo dedicado a la obra de esta artista colombiana busca responder a la necesidad apuntada por periodistas e investigadores de "elaborar estudios más acuciosos sobre la fundamental labor de las comentaristas visuales de opinión en las diversas regiones culturales latinoamericanas" (Uribe-Duncan 15). Por otro lado, busca ahondar en la conciencia feminista de su obra con un estudio analítico de la visión ginocéntrica que nos ofrece Nani de la condición de la mujer en la historia a través de su personaje Magola.

El trabajo se enfoca en tres de sus obras: la novela gráfica, Magola: La verdadera historia de Eva (en adelante, MVHE); y los blogs sobreviviendoenpareja.blogspot.com (en adelante, SEP) y Mujer y caricaturista (en adelante, MYC). La parte inicial dedicada a MVHE, explora las estrategias de subversión y revisión que emplea Nani en la reescritura del relato bíblico judeo-cristiano de la creación de la primera pareja. La segunda parte, enfocada en el blog $S E P$, comenta el uso de un estilo ginocéntrico basado en imágenes de encierro y escape y en metáforas corporales, recuperado de una tradición de escritura femenina de siglos. La tercera y última parte de este estudio se centra en el blog $M Y C$ y aborda los mecanismos usados por Nani para dar voz a su lucha por la emancipación y defensa de los derechos humanos de la mujer, específicamente los de la mujer creadora, históricamente reprimidos en latitudes y tiempos diferentes.

Este estudio se basa, por un lado, en la discusión que hace la crítica austro-americana Gerda Lerner, en The Creation of Feminist Consciousness, de las estrategias, entre ellas la reinterpretación de la Biblia, que desde las místicas medievales han debido usar las mujeres autoras para afirmar su 
derecho al conocimiento y la autoría de su propia historia. Complementa esta discusión, el estudio de John Wilcox en Women Poets of Spain, I860-1990: Toward a Gynocentric Vision sobre la visión ginocéntrica que adoptan algunas poetas españolas de los siglos diecinueve y veinte con el fin de "críticar, desmitificar, subvertir y revisar la estructura androcéntrica de su cultura y ofrecer textos alternativos" (8, mi traducción).

El uso de estas fuentes de interpretación, tan aparentemente removidas del contexto espacial y temporal de Nani, se funda en la importancia de destacar que esta tarea de "críticar, desmitificar, subvertir y revisar la estructura androcéntrica de su cultura" y "de ofrecer textos alternativos" no es una tarea exclusiva de la mujer de hoy sino un derecho por el que han luchado autoras de diferentes espacios y tiempos (Wilcox 8, mi traducción). Extrapolando el comentario de Sandra M. Gilbert y Susan Gubar en el prefacio a Madwoman in the Attic sobre poetas y escritoras de épocas y geografías diferentes, sorprendería la coherencia entre los temas y las imágenes usados por Nani en sus viñetas y los de poetas y escritoras españolas de los siglos diecinueve y veinte, cuyos contextos distan entre sí no solo histórica sino también culturalmente. La conexión, sin embargo, resulta menos sorpresiva cuando nos detenemos a examinar la exclusión sistemática de la mujer de la educación "throughout historical time in every known society" (Lerner, Creation of Patriarchy 5). Esta contradicción entre la centralidad de la mujer como agente y actora en la sociedad y su marginalización en el proceso de crear sistemas de significado y métodos de interpretación, es la fuerza que, argumenta Lerner, mueve dinámicamente la lucha de la mujer en contra de su condición: "This coming-intoconsciousness of women becomes the dialectical force moving them into action to change their condition and to enter a new relationship to maledominant society" (Creation of Patriarchy 5). Es la presencia de esa consciencia femenina en su obra lo que une a Nani a una extensa tradición de mujeres creadoras a lo largo de la historia y la geografía. Además, la natural habilidad común al cómic y a la poesía de crear poderosas imágenes de gran intensidad lírica facilita y permite a la autora dar expresión gráfica a su visión ginocrítica de la lucha de la mujer por la igualdad de género y sus derechos humanos (Arnold).

MAGOLA: LA VERDADERA HISTORIA DE EVA: SUBVERSIÓN, REVISIÓN Y AFIRMACIÓN $M V H E$ es una parodia del relato bíblico judeo-cristiano de la creación de Adán y Eva, o más bien de Eva y Adán. A través de este relato paródico del Génesis, Nani hace una animada desconstrucción de la creencia en la natural inferioridad de la mujer y en su dependencia del hombre, impuesta por designio divino, e inscribe su historia como verdadera. ${ }^{3} \mathrm{Al}$ utilizar la Biblia como referente, Nani hace uso de una tradición iniciada por las místicas 
medievales y seguida por otras valientes escritoras a lo largo de la historia (Lerner, Creation of Feminist Consciousness 88). Así como sus congéneres medievales se apropiaron de su experiencia mística, Nani se apropia de su experiencia como caricaturista para desmitificar, subvertir y corregir la estructura androcéntrica del texto bíblico del Génesis, y crear un texto alternativo, ginocéntrico en el cual inscribir su historia, en la que ella se imagina un ser autónomo e independiente.4 Aprovecha también la capacidad arcaica de la imagen gráfica que le permite, a través de símbolos metonímicos, ubicar la narración bíblica en el presente dentro de un contexto geográfico colombiano (Lemos-Alonso II96-98).5 La ingeniosa combinación de estos dos elementos narrativos, el de la historia con sus connotaciones argumentales y retóricas que invitan a la reflexión; y el del dibujo con su capacidad denotativa de ubicar el tiempo y estos conocidos personajes bíblicos en el presente y dentro del contexto geográfico colombiano gana la simpatía del lector y genera su identificación con esta nueva versión de la historia bíblica. La simpatía del lector surge de la percepción de la historia bíblica como sinédoque de la sociedad colombiana. ${ }^{6}$

MVHE básicamente relata la fábula judeo-cristiana del Génesis, pero subvierte su autoridad a través de alteraciones en los roles de los protagonistas, y la intrusión de la voz narrativa que continuamente interrumpe la historia para corregirla. Las intervenciones de la voz narrativa son fácilmente identificables por su tipografía más oscura, de tamaño y estilo diferentes a los de la voz de los personajes en la historia: Dios, Eva (Magola), Adán y la serpiente. 7 Ya que las viñetas no tienen marco ni canaletas, la posición de los comentarios de la voz narrativa en la hoja varía para dar interés visual y contrastar armónicamente en la página con los comentarios de los personajes. Por su lado, las intervenciones de los personajes aparecen insertadas dentro de globos cuyo trazo puede ser rectilíneo, ondulado o anguloso, dependiendo del estado anímico del personaje que habla: entrecortado si se trata de un secreto o susurro, o en forma de copos de nieve, si se trata de un pensamiento. La ausencia de color enfatiza la tensión entre la luz y la oscuridad, añadiendo al dramatismo de la historia.

El discurso narrativo de la fábula de $M V H E$, podríamos decir, se desarrolla cronológicamente en las siguientes partes: el principio; la creación de Eva (Magola) y Adán; la caída y expulsión del Paraíso; y la usurpación del texto.

EL PRINCIPIO

Una voz narradora anónima nos introduce dentro de la fábula ubicándonos en un tiempo bíblico sin espacio: "Al principio de los tiempos reinaba el 
caos". ${ }^{8}$ Inmediatamente después introduce al personaje creador, una mujer, a quien podríamos describir como otra versión de Magola pero mayor en edad, subida de peso y de pechos redondos. Por las circunstancias de su nacimiento (nace del caos) en el relato de Nani, esta Dios mujer se podría asociar miméticamente con la Madre Tierra, conocida como Gaia, la más antigua de las deidades griegas. Iconográficamente, entre los atributos de la deidad griega se encuentran una serpiente, una cornucopia, flores y frutas (The Encyclopedia of Classical Mythology 57). En MVHE, el caos está representado por una mancha negra, de una de cuyas esquinas cuelga una media larga de lana rondada por moscas. El uso del blanco y negro en el dibujo resalta el contraste entre el orden y el caos. La presencia de la media de Magola sugiere que Magola es parte del caos, del desorden; estableciéndose así, desde un principio, su inconformidad frente al orden patriarcal y surgiriendo, quizás, según quién mire, la necesidad de contenerla, de disciplinarla. Acto seguido, aparece Dios, flotando sobre una nube, en el acto de crear la luz (encendiendo una bombilla). La luz de la bombilla revela la naturaleza del desorden: un universo recién nacido, latas de bebida aplastadas, un cenicero y, de nuevo, una media de Magola tirada en el piso. Ante esta visión, Dios, con ojos desconcertados y sosteniendo una escoba en la mano, mira al lector y comenta, "Esto está hecho un asco". La voz omnisciente agrega: "Y Dios, que era muy hacendosa, prendió la luz y se puso a ordenar..." (fig. I).

Con esta introducción al Génesis, Nani se apropia de tres de las estrategias que las místicas medievales usaron en su esfuerzo por afirmar su voz: la reconceptualización del sexo de Dios haciéndola mujer; el establecimiento de una nueva simbología para hablar de lo divino a través de la relación metonímica entre la escoba y Dios; y la interpretación crítica del relato bíblico en la que se expone el carácter misógino de dicho relato (Lerner, Creation of Feminist Consciousness 47). A diferencia de los atributos de Gaia (cornucopia, flores y frutas), esta Dios-mujer se asocia con una escoba. La escoba la confina al espacio doméstico y connota su inferior capacidad como mujer para intervenir y actuar en el dominio público. Dios resulta así victimizada en este relato por razón de su sexo. A través de estas estrategias, la autora desmitifica, subvierte y revisa el texto patrístico desmantelando su autoridad e inscribiendo la experiencia de la mujer en el relato de la creación.

Poco a poco, la voz de la narrativa se va inmiscuyendo en la historia a través de comentarios sesgados que contribuyen a desmitificar la naturaleza masculina del sexo de Dios. Esta Dios mujer no es una "diosa como todos los hombres quisieran". Su carencia de atractivo frustra las expectativas que la mirada androcéntrica ha impuesto sobre el cuerpo de la mujer, el ser hermosa y deseable. Al no llenar estas expectativas, Dios debe 
asumir otra función dentro del orden patriarcal establecido, el de suegra. El símil anticipa así la tensión que, a medida que avanza el relato, se desarrollará entre Dios y Eva (Magola). Atendiendo al disgusto de Dios ante el símil, la voz narrativa se corrige y cambia el símil de suegra al de madre "para no herir susceptibilidades".

La intención auto-deprecativa (retracción, autocorrección) y deprecativa (insulto) en el humor de esta viñeta, confirma que la voz narradora es consciente del poder catártico y empoderador de este tipo de humor y de su recurrencia en el humor femenino (Walker y Dresner 175; Stillion y White 219-232). Dicen Walker y Dresner: "laughing at one's shortcomings is not only a way of diminishing their importance ... but it is also a technique for cleansing them of pejorative connotations imposed by the dominant culture, and, thereby, turning them into strengths" (I75). Añaden las críticas, "the use of humor by women against women, when it is used to advance ideas that might conflict with those of the male establishment about women's roles and prerogatives, represents a step toward empowerment rather than capitulation" (Walker y Dresner i75). Las técnicas del humor auto-deprecativo y deprecativo de mujer a mujer convierten una debilidad (la tensión entre suegra y nuera) en un punto fuerte (la solidaridad entre mujeres) ya que para el lector lo que resalta no es la tensión entre ellas, sino la victimización que, por ser mujeres, ambas sufren.

El empoderamiento que surge de la denuncia y de la liberación del yugo del texto bíblico, anima a la voz narrativa a incrementar las instancias de su inserción dentro de la narración de manera más obvia cada vez, revelando que el nuevo texto es una meta-cita de la versión bíblica del Génesis. 9 Se sirve de la ironía, a través de comentarios paratextuales, para denunciar la inautenticidad del código patriarcal y desmontar el mito de la omnipotencia del creador. En tono jocoso, la voz narrativa, mostrándonos a través del dibujo a Dios muy ocupada poniendo todo en orden, nos revela que después "se acordó que era Dios y utilizó su magia para que no fuera tan difícil". Y comenta: "Como todas quisiéramos", ilustrando este deseo con una gráfica de Dios muy feliz con los brazos al aire haciendo malabares con los planetas. La imagen y el texto trabajan en estilo entrecruzado, es decir, ambos se complementan pero a la vez confieren información separada (McCloud izo). Por un lado, el texto provoca la risa, al señalar la incongruencia, evidente para sus congéneres ("como todas quisiéramos"), entre la creencia en la omnipotencia de Dios y la realidad, ya que cuando se trata de los quehaceres domésticos, aún Dios necesita ayuda.' Por otro lado, el dibujo evoca de manera nostálgica los poderes mágicos no de Dios, sino de una estilizada bruja contemporánea, la fantástica Samantha, de la serie Bewitched (1964- 
1972), cuyos poderes mágicos le permitían hacer sus deberes domésticos con un respingo de la nariz.

LA CREACIÓN DE EVA Y ADÁN

Aludiendo a la creación de Eva (Magola), la voz narradora de nuevo se desvía de la versión original, a la que ella llama guión, subrayando su carácter ficticio y teatral, para retomar el cuestionamiento de la omnipotencia divina. A partir de la creación, Dios aparece ahora al mismo nivel de su creación (Eva/Magola), sugiriendo ya no ser un poder superior y haberse contagiado de la inferioridad de ésta para ejecutar empresas difíciles. Con su comentario "Dios quería que fuera su mejor obra, pero le salió de lo más normal...", la voz narradora subraya la susceptibilidad de esta Dios al error por ser mujer. El lector o lectora solidario infiere que, al igual que cualquier ama de casa, Dios se cansa y olvida detalles como el implante de pecho de silicona, que aparece tirado en un rincón de la página del dibujo que ilustra la creación de Eva (Magola) (fig. 2). Texto y dibujo se entrecruzan aquí, de nuevo, para proveer más información independientemente. Por un lado, la frase "de lo más normal" refuerza el cuestionamiento de la omnipotencia divina. Por otro, el dibujo de esta Eva (Magola) desnuda, "narizona" y "recta como una tabla de planchar" establece una clara referencia intertextual con el personaje creado por la autora en Así es Magola ("Nani: Humor femenino sin feminismo"). Al crearlas "de lo más normal", tanto Dios como la autora liberan a Eva y a Magola de la erotización de su sexo, condición que, como señala Lerner, se utiliza en los textos patrísticos eclesiásticos para culparla del pecado original y mantenerla subyugada (Creation of Feminist Consciousness I4043).ri Dios decide que, "como estaba cansada", dejaría a Eva (Magola) tal como le quedó, "y pensó que más adelante inventaría el maquillaje". Con esta decisión de Dios, se establece que el cuerpo de la mujer quedará para siempre sujeto a la manipulación de otros sin que ella tenga poder de decisión. Se anticipa también, a través de la presencia del implante de silicona, la transformación física y la ansiedad psicológica acerca de su apariencia, a las que la sociedad de consumo la someterá para responder a los intereses y deseos del hombre, ajenos a los suyos.

La tendencia a transformar del cuerpo de la mujer para conformarlo a los ideales de la estética masculina es reforzada más adelante cuando Dios y Eva (Magola) negocian acerca de la creación de Adán. Dios trata de convencerla de que si le sacara una costilla para crear a Adán, quedaría con cintura. Eva (Magola), a pesar de ser plana como "una tabla de planchar", no está convencida porque le teme a la anestesia general. Sin atender a sus protestas, Dios le saca la costilla y Eva (Magola), al ver que había quedado con una cicatriz y sin cintura le pide a Dios una indemnización. De nuevo, el 
reconocimiento de una debilidad (el temor al dolor) se convierte en un signo de fortaleza e independencia en Eva (Magola) al pedirle a Dios una indemnización. La cicatriz de Eva (Magola) se convierte en una alegoría de la manipulación y el abuso que ha sufrido y sigue sufriendo el sexo femenino a manos de la sociedad patriarcal; la indemnización, a su vez, en una metáfora de la reparación que todas las mujeres querrían reclamar a la Iglesia católica y a la sociedad, por siglos de maltrato, abuso y manipulación.

Otra desmitificación relacionada con el cuerpo de la mujer en MHVE se introduce con el mandato divino de la reproducción. Cuando al presentar a Adán y Eva, y "para romper el hielo" Dios les dice "creced y multiplicaos", la voz narradora reporta que "Adán hizo mucho caso". Como hemos visto anteriormente, es en el entrecruce de texto e imagen que el lector entiende las dimensiones del litote "Adán hizo mucho caso" (fig. 3). El texto nos da una idea atenuada de lo que realmente sugiere la imagen. En la imagen vemos a un Adán, dominado por el afán sexual, persiguiendo frenéticamente a Eva (Magola), quien huye despavorida de su ataque. La combinación de texto e imagen denuncia la violencia que tal mandato ha ejercido sobre la mujer, entre ellas el abuso doméstico, el acoso sexual, el feminicidio. Esta denuncia en la viñeta invita a una reflexión que va más allá de la simple desmitificación y subversión del texto. Invita a inscribir el cuerpo de la mujer como suyo y a hacerla dueña única de la decisión de reproducirse, eliminando todos aquellos agentes que como la Iglesia católica y el estado se han tomado la libertad de decidir por ella.

LA CAÍDA Y LA EXPULSIÓN DEL PARAÍSO

En la representación de la caída y expulsión del Paraíso, $M V H E$ repite casi textualmente el texto bíblico del Génesis. Eva (Magola) y Adán desobedecen, Dios se enfurece y envía a un ángel a sacarlos del Paraíso. Como castigo Dios les asigna esferas separadas a los dos. Eva (Magola) queda relegada a la esfera privada del hogar y a la tarea de reproductora ("parirás con dolor y la cesárea tardará en ser inventada"); y Adán a la esfera pública ("Adán será condenado a ganar el pan para su familia, con el sudor de su frente"). El relato de $M V H E$, sin embargo, no termina con la expulsión del Paraíso. Tiene un último paso: la usurpación del discurso de Eva (Magola) por Adán.

LA USURPACIÓN DEL TEXTO

Las dos últimas viñetas presentan, por un lado, a Eva (Magola) en una cueva, embarazada y rodeada de ollas y niños. Eva (Magola), evidentemente adolorida y agotada, nos dirige una mirada sesgada y una mueca de descontento, pero ya no habla, ha quedado silenciada. El único texto en la viñeta viene de la voz narrativa que comenta: "quedaría relegada para siempre al hogar, trabajando muy duro y sin paga...". Los puntos 
suspensivos connotan la continuidad de una larga historia de encierro, silencio, abuso y falta de reconocimiento. En contraste, en la siguiente hoja, la voz narradora comenta, "mientras [tanto] los hombres escribían la historia y la cambiaban a su antojo". En esta última viñeta aparece Adán sentado sobre una piedra, aderezado con un turbante. Con una sonrisa de satisfacción, y en posesión de un lápiz y una gruesa tabla, escribe: “...Y Dios creó a Adán a su imagen y semejanza...". Los puntos suspensivos del inicio de la oración indican la usurpación del texto de Eva (Magola), antes de la Caída, cuando aún ella tenía voz. Los puntos suspensivos al final de la oración, como en los del texto con que concluye la voz narrativa la historia de Eva (Magola), comunican que la historia continuará, pero esta vez es Adán quien la escribe y será la que todos conocemos.

Al final en $M V H E$, como en el Génesis, es Eva (Magola) la que pierde; sin embargo, el libro entero cuestiona el valor de una re-escritura que simplemente sustituya un texto excluyente por otro, un estereotipo por otro. Dado que el estereotipo se basa en una mirada parcial y excluyente del otro; para no caer de nuevo en el mismo error, en lo dejà dit, el nuevo discurso tendría que ser un discurso inclusivo y plural. El paso inaugural a la posmodernidad, según Lang, sería, pues, "the renunciation of all pretensions to a singular voice, by simultaneously assuming a multiplicity of discourses (without quotation marks)" (59). Esta sugerencia parecería promover una ruptura de las distinciones artificiales entre un sexo y otro, entre las esferas privada y pública que se les han asignado. Esta es la misión en que se embarca la autora en sus siguientes obras.

SOBREVIVIENDO EN PAREJA: UNA VISIÓN GINOCÉNTRICA

Esta parte del artículo usa como referente primario las viñetas en el blog de la autora, $S E P^{12}$ y explora desde un nuevo ángulo, el de la imagen poética ginocéntrica, cómo texto e imagen en las viñetas de Nani contribuyen a desconstruir, subvertir y revisar el discurso androcéntrico. ${ }^{13}$ A SEP añadiremos comentarios pertinentes a MVHE.

Como sostenía Lerner, si consideramos la importancia que para la mujer creadora, desde las místicas medievales hasta el presente, tiene el formar una audiencia a quien comunicar su experiencia desde una perspectiva de mujer, no es difícil entender el atractivo que la imagen poética, metáforas y símbolos líricos tuvieran para ellas, justamente por su gran valor evocativo y su poder de abstracción y complejidad cognitiva. En Women Poets of Spain, I860-1990: Toward A Gynocentric Vision, John Wilcox estudia el uso de estas imágenes con una visión ginocéntrica en poetas españolas desde mediados del siglo diecinueve hasta finales del veinte. Explica Wilcox que aunque el uso de estas imágenes no es exclusivo de las poetas mujeres, éstas tienden a aparecer más frecuentemente en la poesía 
de mujeres que en la de hombres, por lo cual él las clasifica como ginocéntricas ( 13 ). Entre estas imágenes están el palimpsesto, la imagen exoesquelética, la escritura corporal y la no linealidad.

Textos palimpsésticos con una visión ginocéntrica serían aquellos que, según Gilbert y Gubar, esconden debajo de la superficie de un texto androcéntrico significados ocultos que subvierten ese orden (73). De acuerdo con esta descripción, el relato entero en $M V H E$ sería un palimpsesto ya que usa la historia del Génesis, un texto androcéntrico, para subvertir y revisar sus principios desde una mirada ginocéntrica. El recurso del humor deprecativo y autodeprecativo de la parodia, estudiado en la primera parte de este artículo, con el doble propósito de disminuir el efecto peyorativo y convertirlo en fortaleza, adquiere ahora una dimensión poética a través del recurso del palimpsesto. Así como Medusa, en el símil de Wilcox, atrae con su belleza a los hombres para después atraparlos con las serpientes de su pelo y convertirlos en piedra (13), igualmente Nani usa la parodia en $M V H E$ con aparente intención lúdica para después hacer migajas el texto androcéntrico a través del palimpsesto. El eficiente empleo del entrecruce entre texto e imagen, le permite a Nani filtrar ingeniosamente su voz dentro del texto patrístico, haciéndole un guiño al lector quien sonríe mostrando empatía hacia la actitud iconoclasta de la protagonista.

En el blog $S E P$, ז4 la viñeta "Gracias señor, acaba usted de darme toda la razón" ${ }^{15}$ (fig. 4) podría también considerarse un palimpsesto en cuanto Magola, con un micrófono en la mano, aprovecha el discurso misógino del espectador anónimo para reafirmar su tesis "iLas mujeres sólo pedimos igualdad y respeto!" Esta viñeta de tres paneles exhibe un selecto uso de recursos gráficos, a saber: el uso de la línea impecable del globo que encierra el discurso de Magola, en contraste con las líneas agudas y quebradas que enmarcan el insulto misógino del espectador; la luz de la cámara sobre Magola en el escenario que la expone como si fuera un blanco en contraste con el anonimato de la multitud bajo el que se encubre su agresor y que le impide a Magola identificarlo; y la posición central del insulto enmarcado por los dos paneles que abren y cierran la viñeta. La selección del texto es igualmente efectiva: el lenguaje agresivo del insulto, "¿Usted quién se cree para venir a hablarnos así? ¡Lesbiana, feminazi, histérica!", resalta en obvia disonancia con el lenguaje atemperado y civil de Magola, "Gracias señor". En esta viñeta, el hábil uso de recursos visuales tiene un efecto similar al de los espacios en la poesía concreta, ya que llama la atención sobre el texto. ${ }^{16} \mathrm{La}$ combinación de estos dos recursos contribuye efectivamente a generar una experiencia única, a la vez estética, intelectual y emotiva para el lector.

Como ejemplos de textos exoesqueléticos, Wilcox menciona aquellos que usan un estilo de expresión severo, rígido, frío en oposición a un estilo suave y maleable, cualidades estas últimas que el discurso androcéntrico 
asigna a la mujer para subrayar su naturaleza débil e inferior (I3). Imágenes de objetos duros como el metal o la piedra funcionan como una coraza protectora del ego fragmentado de la mujer (Wicolx I3). La viñeta "¿Así? ¿O más sexy?" (fig. 5) muestra a una Magola, que seductoramente se desabrocha la blusa para supuestamente revelar sus pechos. Sin embargo, al desabrocharse la blusa, Magola exhibe una estantería de libros en el lugar de sus pechos. La pasta dura de los libros al igual que la rigidez de la madera de la estantería forman una barrera que protege su cuerpo de la mirada indiscreta del espectador. Por otro lado, los libros, metáfora del conocimiento, se convierten en sinécdoque de mujer, ya que son parte de su ser. La imagen, sin embargo, también subraya la vulnerabilidad que a causa de su sexo experimenta la mujer, y la sentencia de que por ser mujer siempre será vista por los hombres como un objeto sexual en vez de un ser pensante. De nuevo, la combinación de la imagen y el texto se conjugan excelentemente en esta viñeta para crear una experiencia lírica, personal y poderosa para la lectora o lector empatéticos.

La escritura corporal basada en imágenes que evocan movimiento, fluidez y vida sería una escritura opuesta a la escritura exoesquelética, explica Wilcox (13). Añade que este estilo de escritura promovido por las feministas francesas busca reconceptualizar la relación de la mujer con su cuerpo, y el disfrute del mismo (Wilcox I3). Esta reconceptualización sugiere una síntesis entre mujer y naturaleza, unión que tradicionalmente ha sido usada por el hombre occidental para alienar a la mujer. La viñeta “¡Mi cuerpo es mío y punto!" (fig. 6) nos muestra las piernas sin afeitar de Magola que ella exhibe sin recato ni pudor mientras toma un baño de tina. La extensión de la viñeta en cuatro paneles sugiere el disfrute y relajamiento de Magola y le da tiempo para reflexionar y expresar su opinión sobre su cuerpo: "Mi cuerpo no es un templo ni un campo de batallas..."; "No es un trofeo para nadie..."; "No le pertenece ni a la iglesia, ni al estado, ni a mi pareja...”; y concluir con un rotundo “iMi cuerpo es mío y punto!”. Es evidente en esta viñeta que Magola ha acogido gustosamente el reencuentro con su cuerpo. Este reencuentro es celebrado con una sonrisa aprobatoria por sus espectadoras. El espaciamiento entre los paneles, la sonoridad del paralelismo sintáctico de las oraciones ("Mi cuerpo no es... ni.../ no es.../ no le..."), y el exclamativo final hacen que el texto en esta viñeta se lea casi como un poema, ofreciéndole al lector a la vez una experiencia estética e intelectual.

Finalmente, la escritura no lineal, explica Wilcox, se distingue por un estilo de discurso que interrumpe el flujo de la sintaxis con silencios, preguntas, repeticiones, voces múltiples y metáforas de exceso para enfatizar la circularidad, la repetición, la fragmentación, la carencia de límites entre realidad y fantasía (I4). Este estilo se opone al estilo lineal, 
lógico y estructurado del pensamiento masculino. La viñeta "La sociedad nos pide autoestima" (fig. 7) ilustra el círculo vicioso en el que queda atrapada la mujer que se atreve a ser independiente y a autoafirmarse. Cinco imágenes consecutivas de una Magola inestable, sujeta a continuos cambios emocionales, del desespero, a la ira, al llanto reprimido; de estos a la seguridad y confianza en sí misma y finalmente a la derrota y parálisis total, complementan con intenso dramatismo el comentario final del personaje: "La sociedad nos pide autoestima, pero los hombres abandonan a las mujeres que la tienen". La viñeta es un homenaje épico al heroísmo de la mujer que sobrevive a pesar de un sistema patriarcal que la ha mantenido sujetada, silenciada y reprimida por siglos, y que la ha castigado, menospreciado y calificado de loca, desubicada, incapaz o marimacha. La amenaza del abandono es sinónimo del riesgo al ostracismo y discriminación a que se han visto destinadas aquellas mujeres que se han atrevido a pensar, a opinar. Es la usurpación final de uno de los derechos humanos más sagrados, el derecho a la libre expresión. El lector o lectora no puede menos que sentir una empática emoción lírica con la protagonista.

MUJER Y CARICATURISTA: UN FORO HACIA LA EMANCIPACIÓN

$M Y C$ es otro blog de la autora; se publica semanalmente desde 2013 en el periódico El Espectador. Las viñetas en este blog suelen ser las mismas o de temática muy similar a las que aparecen en el blog SEP. Lo que distingue a este blog es el hecho de que cada entrada consiste en un ensayo breve acompañado de una viñeta que ilustra el tema. Nani, desde su perspectiva de mujer y artista gráfica, usa este espacio virtual para crear un foro de discusión sobre temas relativos a la igualdad de género; los derechos humanos de los marginados sociales, especialmente de la mujer; y al rescate, defensa y reconocimiento de la labor de hombres y mujeres en el mundo artístico. ${ }^{17}$

La creación de un foro apropiado para su labor de portavoz en favor del empoderamiento y los derechos humanos de la mujer nos conecta con el último de los retos que Lerner menciona debían superar las escritoras medievales después de conseguir ser aceptadas como autoras de sus textos; de que se les reconociera el derecho a pensar por sí mismas; y de que se considerara su experiencia como mujeres una fuente válida de conocimiento (Creation of Feminist Consciousness 47-48). Dice Lerner: "Once these obstacles were removed, writing women still faced the problem of finding or creating audiences appropriate to their work" (47). Y agrega que si su audiencia era masculina, "they needed to defuse and deconstruct the patriarchal frame of reference which devalued and trivialized their work. They ... needed to minimize the separateness and uniqueness of their female experience ... often ... distorting, disguising or trivializing their own 
experience" (48). Si se trataba de un público femenino, tenían que encontrar símbolos y códigos lingüísticos que les permitieran a sus lectoras reproducir el proceso que las escritoras mismas tuvieron que seguir para llegar a formular sus pensamientos (48). Este proceso las llevaba a evocar y a apropiarse de fuentes de conocimiento que las mujeres se habían negado para poder sobrevivir en un universo patriarcal (48). Como para estas escritoras medievales, la tarea que ha enfrentado Nani es radicalmente diferente a la de los hombres en su campo cuya autoridad no se cuestiona y cuyo derecho a expresarse desde su experiencia como hombres se da por sentado. Los cibermedios han hecho que esta labor sea aún más arriesgada para los autores, ya que, como observamos en la discusión de la viñeta "Gracias señor, acaba usted de darme la razón" (fig. 4), el anonimato propio de estos medios permite feroces insultos, ataques y amenazas a la autora de este blog..$^{8}$

Nos detendremos a comentar la entrada "Reto a los matones de Internet" por la escalofriante vigencia que esta revela de los obstáculos que sufrieran las mujeres escritoras medievales en su momento (Lerner, Creation of Feminist Consciousness 47-48) y que siguen sufriendo las mujeres creadoras de hoy, de manera aún más sofisticada, si se quiere, en su saña. En su ensayo, la autora denuncia a los que "escriben comentarios vulgares, que descalifican, que juzgan ... detrás del cómodo camuflaje de una pantalla del computador". Esta cita expone la fobia y el reto que inspira la mujer que escribe, que reclama independencia de pensamiento y que se atreve a usar su experiencia de mujer, no la del hombre, como fuente de conocimiento. "Reto a los matones de Internet" pone en evidencia que la mujer creadora sigue siendo vista como una amenaza al género masculino y al orden patriarcal. De admirar es la valentía de esta autora que reta "de frente y sin miedo" a sus atacantes a que "escriban ... que lo hagan de forma perfecta, que además tengan un texto interesante, que logren miles de visitas".

Esta entrada acompaña a una de las imágenes de la autora más reproducidas en periódicos y revistas, la de Magola atrapada dentro de un vaso de agua. En una secuencia de tres imágenes sin marco, Magola adopta difíciles posiciones tratando de salir del vaso. Debajo de las imágenes se lee el mensaje: "Recuerda. No es tan fácil ahogarse en un vaso de agua" (fig. 8). El uso del imperativo "recuerda" sugiere que el texto de la imagen va dirigida a una audiencia masculina que ha criticado las técnicas de composición escrita de la autora y que la acusa de "ahogarse en un vaso de agua". Ante la devaluación y trivialización que esta audiencia masculina hace de su trabajo, Nani contesta de una manera opuesta a la que las escritoras medievales debieron hacer. En vez de minimizar aquello que hace su experiencia como mujer única y diferente a la del hombre, Nani maximiza y exagera esa experiencia con la imagen de Magola ahogándose en un vaso 
de agua. La imagen podría calificarse como una imagen exoesquelética dada la naturaleza fría y dura del vaso que la encierra. Sin embargo, en vez de ser una coraza protectora, como en el caso de los libros que cubren sus pechos en la viñeta "¿Así? ¿0 más sexy?" (fig. 5), esta es una imagen de encierro y sofocamiento que ilustra lo que la autora ha tenido que vivir; su experiencia como mujer, como artista gráfica y como escritora frente a un mundo masculino que siempre ha minimizado y trivializado su obra.

El mensaje, "Recuerda. No es tan fácil ahogarse en un vaso de agua", podría calificarse a su vez como un palimpsesto, una apropiación del texto masculino. La autora gira el texto como si fuera un espejo e invita a su ofensor a que se mire en él, animándolo a meterse dentro del vaso y a salir de él. La ironía consiste en que, aun para ahogarse en un vaso de agua (es decir, para hacer una labor que muchos pueden juzgar fácil o trivial) es necesario tener talento, haber estudiado y tener disciplina. Los hombres, cuya autoridad nunca ha sido cuestionada, no pueden juzgar las dificultades que para ser reconocidas por su trabajo, las mujeres deben enfrentar. Mientras que las escritoras medievales de quienes nos habla Lerner probablemente no habrían tenido una audiencia mezclada de hombres y mujeres a la vez, la audiencia de Nani es una mezcla de ambos sexos. Por lo tanto, tiene que, simultáneamente, desconstruir el referente patriarcal que la juzga, sin distorsionar su experiencia como mujer, y a la vez, encontrar imágenes, y códigos lingüísticos que le permitan reproducir, para su audiencia femenina, el proceso de humillación y superación que le ha tocado vivir. Y debe hacer esto, de modo tal que sus palabras sirvan de inspiración y empoderamiento, y no de rechazo, a otras mujeres. Nani contribuye así a mantener viva la antorcha que encendieran sus congéneres medievales tanto en el reclamo del derecho humano a la libre expresión, como en la promoción del derecho a la igualdad de género en la esfera pública.

Otra de las entradas en este blog que vale la pena destacar es la titulada "Cuando tener vagina es censurable". En este ensayo Nani cuestiona la censura que el Tribunal Administrativo de Cundinamarca pusiera a la exposición de la artista María Eugenia Trujillo titulada "Mujeres ocultas", destinada a inaugurarse en el Museo Santa Clara de Bogotá en agosto de 20I4. En entrevista con El Espectador, Trujillo explica que en su exhibición usa "objetos que evocan custodias, pero no son realmente custodias" (Magalón Llano). El objetivo de la exposición agrega la artista, "es sacralizar la idea de lo que es la mujer". La censura se basa en sesenta y cinco demandas presentadas ante dicho tribunal con el siguiente texto: "[L]a exposición emplea las imágenes religiosas y elementos del culto católico y las combina con sugestivas representaciones de partes del cuerpo femenino. Se ridiculizan e irrespetan las creencias de la población católica del país"(Magalón Llano). 
Nani abre su entrada "Cuando tener vagina es censurable" denunciando a las religiones de cualquier tipo por la anulación de la mujer en todas sus expresiones. Resume las premisas de tal anulación así: "La mujer es la culpable del pecado original, la mujer debe cubrirse de pies a cabeza ya sea con un hábito o con un burka, la mujer no es digna de hablar en un púlpito ni de ocupar puesto de relevancia. $Y$ todo esto porque las mujeres incitan al pecado con sus cuerpos”. Y pregunta, “No será que el "pecado” está en el ojo de quien mira?". Nani continúa su argumento subrayando la experiencia de la artista mujer para interpretar su cuerpo: "Solamente una mujer puede ser capaz de ver en objetos similares a las custodias religiosas la representación de una mujer custodiada, oculta, sacrificada", y puntualiza en el hecho de que esta custodia de siglos se vuelve a repetir con la censura de la exposición de María Eugenia Trujillo. Agrega Nani, reflexionando sobre el caso, que esta censura no es solamente del arte sino del "pensamiento femenino, el punto de vista de una mujer artista". Concluye haciendo eco a la artista repitiendo la pregunta: “¿Dónde quedan la libertad de expresión, la libertad de culto, la equidad de género en el arte?"

En su entrada, "Cuando tener vagina es censurable", Nani es distintivamente elocuente al acusar a las instituciones religiosas de perpetuar una visión misógina, "silenciosa y cobarde" y al denunciar a los estamentos reguladores del estado que se toman el privilegio de decidir qué deben o no ver los ciudadanos. Usa su voz para defender no solo los derechos de la artista en particular, sino del arte en general, el derecho a la libre expresión y el derecho de la mujer a su propia experiencia.

La imagen que acompaña a la entrada "Cuando tener vagina es censurable" es igualmente elocuente. Se trata de nueve mujeres, de diferentes formas, tamaños, colores y etnias, cuyos cuerpos desnudos están tapados por un crucifijo negro. Se puede observar que ninguna de ellas tiene boca, sugiriendo su silenciamiento. La última de estas nueve mujeres es Magola, quien mira aterrada al observador. El título de la imagen es "Mujeres ocultas". Por su número, estas nueve mujeres evocan las nueve musas de la mitología griega; sin embargo, por estar en línea, y su cuerpo estar oculto por la cruz negra, parecen representar una lista de criminales. Se sugiere así que el arte es una forma de transgresión y los artistas, por ende, transgresores y criminales. La cruz representa así la anulación de todas las formas de arte y de pensamiento con expresión de mujer. Nuevamente, la imagen exoesquelética resulta ser un recurso apropiado para comunicar la opresión y el ocultamiento de la mujer. Esta cruz, bien metálica o de madera, cubre por entero el cuerpo de estas mujeres negándoles su sexo. Dura, fría, y pesada, la cruz no es un símbolo de protección sino de anulación. Se podría argumentar también que esta imagen sugiere una forma de palimpsesto ya que la cruz oculta, debajo de sí, el cuerpo de la mujer. Al ocultar el cuerpo de la mujer, la cruz oculta todo 
lo que debería pertenecerle a la mujer, su texto, su voz, su escritura, su historia.

"Cuando tener vagina es censurable" trae ecos profundos de MVHE en cuanto ambos, entrada y novela gráfica, respectivamente, tienen un referente religioso: el Génesis en $M V H E$ y la censura religiosa en la entrada del blog MYC. En MVHE, Dios es mujer y, por esta razón, resulta disminuída en sus poderes. Al final, el texto patriarcal prevalece, se establece la separación de las esferas pública y privada entre Adán y Eva, y Eva queda para siempre asociada al pecado original por razón de su sexo. A su vez, la entrada "Cuando tener vagina es censurable" es una triste comprobación de que nada ha cambiado para la mujer desde su inscripción en la historia occidental como la seductora de Adán y la causante de la expulsión del Paraíso Terrenal. Sinónimo de pecado, todo lo que toque Eva se contamina. Aún el arte termina siendo pecaminoso si es hecho por una mujer.

El presente ensayo ha hecho un análisis feminista de tres manifestaciones artísticas de la caricaturista colombiana Nani Mosquera: su novela gráfica $M V H E$ y sus blogs $S E P$ y $M Y C$. En la novela gráfica $M V H E$, nos hemos enfocado en la subversión, revisión, apropriación y reescritura que hace Nani del texto bíblico del Génesis y que la une a una larga tradición de escritura feminista que empezara con las místicas medievales, según revela Lerner en The Creation of Feminist Consciousness. Hemos estudiado cómo esta apropriación en forma de parodia hace uso del humor deprecativo y autodeprecativo, técnicas generalmente usadas por las mujeres, como señalan Walker y Dresner, para generar alivio pero también afirmación y empoderamiento. Hemos también apuntado a la naturaleza arcaica del arte gráfico, es decir a su capacidad de conectar contextos remotos en el tiempo y en el espacio con el presente del lector para buscar una identificación con su realidad.

En la segunda y tercera partes del ensayo, hemos partido del estudio que hace Wilcox del estilo ginocéntrico adoptado por poetas españolas de los siglo diecinueve y veinte en la subversión y revisión del discurso masculino para analizar las imágenes usadas por Nani en sus blogs SEP y $M Y C$. Hemos visto cómo este estilo manifiesto en el uso del palimpsesto, de formas exoesqueléticas, de una escritura corporal y no lineal, en vez de generar la risa genera una reflexión dolorosa que busca llevar al lector de la empatía a la acción. Abordamos la temática de empoderamiento y denuncia de la inequidad de género de los ensayos de opinión que constituyen las entradas al blog $M Y C$ y la valentía con la que Nani lucha por los derechos humanos de la mujer.

Este ensayo es un estudio detallado de la obra de Nani Mosquera que responde al llamado hecho por Uribe-Duncan y que aborda el tema de los derechos humanos y los derechos de la mujer. Considerando que Colombia 
reporta un estado aún precario en la salvaguarda de los derechos humanos de la mujer (Naranjo Morales; Alta consejería presidencial), realizar estudios individualizados que profundicen en la experiencia femenina representada en la obra de estas heroínas de la viñeta colombiana (Magola, Nieves, Aleida, Cándida) y en la de otras importantes artistas gráficas como Elena Ospina, más que una necesidad, es un deber para los investigadores en feminismo.

\section{Saint Louis University}

\section{NOTAS}

I En la entrevista "Nani Mosquera: Una mujer que escribe, dibuja, opina y, encima, hace reír es un peligro", Nani habla sobre la creación de Magola en la Feria del Libro de Bogotá en I995, y expone que decidió crear un personaje diferente a lo que los hombres dibujaban. Bautizó a su personaje Magola y la creó flaca, narizona y de ojos saltones (Bafile). El personaje tiene mucho en común con su creadora. Al igual que Nani, Magola es una mujer mestiza, como la mayoría de los colombianos, de clase media, profesional, casada y con un hijo. Como ella, es feminista y denuncia "sin pelos en la lengua" la inequidad de género. Autónoma e independiente, se declara dueña única de su cuerpo y exhibe con orgullo sus piernas sin depilar. Su pelo es largo y azul, y sus ojos grandes reflejan su espíritu libre, inteligente y combativo. Su esposo, Alberto, es desgarbado como ella, cariñoso y tierno, pero de ojos pequeñitos, sugerentes de una miopía masculina, que, a su pesar, le impide ver o "escuchar" las necesidades de su mujer.

2 En su nota "Heroínas de la viñeta en Colombia”, Magdalena Barrero destaca la labor de personajes como "Nieves" (Consuelo Lago), "Magola” (Adriana Mosquera, Nani), “Aleida” (Vladimir Flórez, Vladdo), “Cándida” (Jairo Peláez Rincón, Jarape) en buscar cambiar la perspectiva cultural de Colombia sobre los abusos en contra de la mujer.

3 Gerda Lerner, en The Creation of Feminist Consciousness, explica que la creencia en la natural inferioridad de la mujer y en su dependencia del hombre data antes de la era cristiana pero que fue después del siglo 3 DC, cuando la Iglesia se consolidó como una institución jerárquica masculina, que los argumentos de esta creencia fueron elaborados en detalle (46).

4 En The Creation of Feminist Consciousness, Gerda Lerner detalla cómo las místicas medievales europeas se apropiaron de su experiencia mística para afirmar su autoridad e independencia y buscar un público para sus enseñanzas (88). Agrega que posteriores escritoras occidentales persistieron en el uso de la Biblia como referente para reclamar su derecho a la igualdad religiosa. Este 
esfuerzo tomó diferentes formas, entre ellas: el desarrollo de símbolos y de un lenguaje femenino para hablar de Dios; la reconceptualización de Dios a la vez como hombre y mujer; la intervención directa de la mujer en la redención y la salvación; y el estudio crítico de la Biblia (88).

5 Basándose en una interpretación de los estudios semiológicos de Barthes en relación a la publicidad (La aventura semiológica), Haizea Lemos-Alonso, en su artículo "La capacidad retórica del humor gráfico: la columna gráfica", plantea un interesante estudio retórico del humor gráfico que permite ubicar este género dentro de los estudios tradicionales del género periodístico bajo la teoría de hibridación de géneros. Lemos-Alonso apoya su argumento en tres características del humor gráfico: su capacidad argumentativa (información icónica connotativa); capacidad retórica (información lingüística) y su capacidad icónica denotada (imagen pura, escenario, personajes).

6 La iconografía usada en MVHE ubica geográficamente la acción en Colombia durante las últimas décadas del siglo veinte. Esta iconografía denuncia sutilmente problemas endémicos de la sociedad colombiana: los hipopótamos sobre los que se recuesta Magola aluden a los especímenes que importara Pablo Escobar, el conocido narcotraficante colombiano, para su zoológico personal y que, veinticinco años después de su muerte en I993, se convirtieran en una amenaza para el ecosistema del país. Por otro lado, el logo en las camisetas que les vende la serpiente a Eva (Magola) y a Adán alude a la marihuana, cuyo cultivo en Colombia ha sido controversial, ya que su demanda es alta, especialmente en el mercado externo, porque las leyes colombianas lo prohíben. Finalmente, el puesto de venta que opera la serpiente alude a las ventas callejeras, fenómeno económico especialmente en Bogotá que poluciona el espacio público, no paga impuestos e incentiva el negocio ilícito (Universidad de los Andes).

7 Dios interviene un total de 9 veces; Eva (Magola), I4 veces; Adán, 4 veces; la serpiente, 3 veces. Algunas de las intervenciones son pensamientos o interjecciones.

8 Puesto que Magola: la verdadera historia de Eva, a pesar de ser un libro, no tiene paginación, se usan las citas del texto para facilitar el análisis de la historia a lo largo del artículo. Se sigue este procedimiento en todas las citas extraídas de MLVHE.

9 En su agudo estudio sobre la ironía y el humor, Candace D. Lang aborda el concepto de la ironía en Barthes como el discurso estereotípico de la doxa (las creencias populares, lo dado) dentro de una cultura. Explica, "Irony, like other codes, is a kind of citation, or repetition of a dejà-dit, but with one essential distinction: irony is a meta-citation, the quotation of other quotes as quotations" (58).

IO Con relación a la incongruencia, que la mayoría de los teóricos del humor asocian con la sorpresa, la dislocación o la inversión de expectativas, Walker y 
Dresner explican, "because the perception of incongruity is based on shared values, beliefs, customs, habits, and experiences, the degree to which genders (and races or ethnic groups) are differentiated by their cultures into separate classes of people will determine the degree to which they can share and enjoy each other's perceptions of the incongruities that make up their humorous visions" (174).

II Lerner, en The Creation of Feminist Consciousness, hace una descripción cronológica de cómo los sucesivos padres de la Iglesia en el medioevo (San Pablo, Timoteo, Tertuliano, Ambrosio, San Agustín de Hipo y Santo Tomás de Aquino) contribuyeron a establecer y perpetuar la visión misógena de Eva a partir de su exégesis de textos claves en el Antiguo Testamento, en particular los textos relativos al Génesis y a la creación de Eva de una costilla de Adán, que más tarde fueran asociados a la Caída en la doctrina cristiana.

I2 Sobreviviendo en pareja es el epónimo de un libro de la autora publicado en España en 2007.

I3 La crítica Sharon Keefe Ugalde diferencia entre los términos subversión y revisión, explicando que subversión es una táctica destructiva que busca desarmar el andamiaje simbólico que ha subyugado a la mujer, mientras que revisión le permite construir su propia identidad y apropiarse del lenguaje existente, transformarlo, moldearlo para expresar su propia experiencia y de esa manera "avanzar de la protesta a la inscripción de su verdadero ser" (Conversaciones I2; "Feminization" I67 y 173).

I4 En general, en sobreviviendoenpareja.blogspot.com la autora recoge viñetas suyas desde el año 2007 hasta el presente, publicadas en El Espectador u otros medios. Aunque las viñetas en el blog tratan temas variados relacionados con la pareja, con la sociedad en general, con eventos del momento en Colombia y en el mundo, para los propósitos de este artículo nos hemos enfocado especialmente en aquellos que se relacionan íntimamente con los derechos humanos de la mujer. A diferencia de $M V H E$, las viñetas en sobreviviendo en pareja.blogspot.com están realizadas en su mayoría en colores primarios, predominando el azul del pelo de Magola y el rojo de su vestimenta. Sin embargo, algunas de las viñetas más antiguas aparecen en blanco y negro.

Mientras MVHE es un relato y podría considerarse como una novela gráfica, las viñetas en los blogs varían entre uno a múltiples paneles con un mensaje único y preciso. El mensaje del texto suele estar complementado por el dibujo en una de las varias modalidades explicadas por McCloud en Making Comics, predominando la modalidad entrecruzada (130).

I5 Utilizo en la discusión parte del texto en la viñeta como título de la entrada para facilidad de referencia. Cada viñeta representa una entrada en el blog.

I6 A tal respecto, Will Eisner comenta que, dado que en el dibujo gráfico las letras mismas son dibujadas a mano, la intensidad y tono que estas agregan al texto las asocian a la imagen o a la poesía concreta (cit. en Tabachnick 4). 
I7 Mencionamos aquí, a manera de ilustración, algunos de los títulos que ilustran la temática que suele cubrir Nani en las entradas a su blog, Mujer y caricaturista: “¿Por qué no hay mujeres caricaturistas?; "Mucho por hacer en equidad de género"; "Santas, vírgenes y berracas"; "Reto a los matones de Internet"; "Vamos a hablar de sexo limpio"; “¿Celebrar o no la vigencia de Mafalda?”; “Cuando tener vagina es censurable”; “¡Shakira qué grande eres!”. Cada ensayo constituye una entrada en el blog.

I8 En respuesta a la pregunta "¿Alguna vez te has sentido amenazada o presionada por tus tiras políticas?", en la entrevista "Nani Mosquera: Una mujer que escribe, dibuja, opina y, encima hace reír es un peligro", Nani declara: "Me han intimidado por medio de las redes sociales y sobre todo desde que escribo también artículos para el diario El Espectador. Algunos hombres se sienten ofendidos por el hecho de que sea capaz de ser caricaturista y además escribir artículos. ¡Una mujer que escribe, dibuja, opina y, encima, hace reír es un peligro! Y su mejor respuesta es ofender y descalificar escudados en un nombre ficticio en las redes. Me han dicho que me dedique a lo mío, que opino con la vagina, que quién me creo que soy, que siga haciendo mamarrachos..." (Bafile).

\section{OBRAS CITADAS}

ALTA CONSEJERÍA PRESIDENCIAL PARA LA EQUIDAD DE LA MUJER. Lineamientos de la política pública nacional de equidad de género para las mujeres. Bogotá: Presidencia de la República. 20I2. Web.

AR N OLD, AN DREW. “Comix Poetics." World Literature Today 8I.2 (2007): I2-I5.

B AF I LE, MAR IZ A. Entrevista con Nani Mosquera. "Nani Mosquera: Una mujer que escribe, dibuja, opina y, encima, hace reír es un peligro." ViceVersa Magazine (2017): S. pag. Web.

B AR Re R O, ma g d L EnA. "Heroínas de la viñeta colombiana." Revista Galáctica, Revista Independiente de crítica cultural. S. pag. Web.

CHute, hillary. "Secret Labor: Sketching the Connection between Poetry and

Comics." Poetry Magazine. July 2013. S. pag. Web.

E ISNe R, W I L. Comics and Sequential Art. Tamarac: Poorhouse, 1985. THE ENCYCLOPEDIA OF CLASSICAL MYTHOLOGY. Englewood Cliffs:

Prentice Hall. 1965 .

gilbert, SAndRa M., y SUSAn GUBAr. The Madwoman in the Attic. $2^{\text {nd }}$ ed.

New Haven: Yale UP, 2000.

L A N G, CAN D A CE D. Irony / Humor: Critical Paradigms. Baltimore: The

Johns Hopkins UP, 1988. 
LEM OS-ALONSO, HAIZEA. "La capacidad retórica del humor gráfico: la columna gráfica." Revista de Comunicación Vivat Academia I4 (2012):

II94-I2O5. Web.

LERNER, GERDA. The Creation of Feminist Consciousness. Oxford: Oxford UP, 1993.

-. The Creation of Patriarchy. Oxford: Oxford UP, 1986.

MAGALÓN LlANO, SARA. "Un caso de censura." El Espectador. 28 agosto 20I4. S. pag. Web.

M C C L O U D, S C O T T. Making Comics. New York: Harper, 2006.

M OSQUERA, ADR IANA. “¿Celebrar o no la vigencia de Mafalda?"Mujer-ycaricaturista. Blogs. El Espectador. Actualidad (2014): S. pag. Web.

—. "Cuando tener vagina es censurable." Mujer-y-caricaturista. Blogs. El Espectador. Actualidad (2014): S. pag. Web.

—. Magola: La verdadera historia de Eva. Bogotá: Editorial La Oveja Negra, 2000.

—. "Mucho por hacer en equidad de género." Mujer-y-caricaturista. Blogs. El Espectador. Actualidad (2016): S. pag. Web.

—. "Nani: Humor femenino sin feminismos." Tebeosfera (2008): S. pag. Web.

—. “Por qué no hay mujeres caricaturistas?” Mujer-y-caricaturista. Blogs. El Espectador. Actualidad (2018): S. pag. Web.

—. "Reto a los matones de Internet." Mujer-y-caricaturista. Blogs. El Espectador. Actualidad (2014): S. pag. Web.

—. "Santas, vírgenes y berracas." Mujer-y-caricaturista. Blogs. El Espectador. Actualidad (2016): S. pag. Web.

—. “Shakira qué grande eres!” Mujer-y-caricaturista. Blogs. El Espectador. Actualidad (2014): S. pag. Web.

-. Sobreviviendo en pareja. Barcelona: Ediciones B, 2007.

- Sobreviviendo en pareja. sobreviviendoenpareja.blogspot.com. S. pag. Web.

—. "Vamos a hablar de sexo limpio." Mujer-y-caricaturista. Blogs. El Espectador. Actualidad (2014): S. pag. Web.

NARANJO MORALES, ANDREA. "Derechos de género: avances y retrocesos recientes en Colombia." Razón Pública. Política y Gobierno (2013): S. pag. Web.

RODRíguez ARÉVAlo, CAROLina. "Cartografía del cuerpo de la mujer/es en el humor gráfico: una mirada feminista.” Tesis de Maestría. Universidad Nacional, Bogotá, 2017.

STILLION, JUdith M., Y HEDY White. "Feminist Humor: Who Appreciates It and Why?" Psychology of Women Quarterly II (1987): 219-32.

T A B A CH N IC K, S TE PHEN. Introduction. Teaching the Graphic Novel. New York: The Modern Language Association of America, 2019. I-15.

U GALDE, SHARON KEEFE. Conversaciones y poemas. La nueva poesía femenina española en castellano. Madrid: Siglo XXI, I99I. 
- "The Feminization of Female Figures in Spanish Women's Poetry of the r980s." Studies in Twentieth Century Literature I6.I (1992): 165-84.

UNIVERSIDAD DE LOS ANDES, COLOMBIA. "Las ventas callejeras son, en escencia, un fenómeno económico." S. pag. Web.

uRIBE-DUNCAN, JEANNETTE. "Mujeres e ilustración crítica." Birkbeck University of London (2015): I-17. Web.

villegas uribe, carlos alberto. "Aportes teóricos para un nuevo paradigma de la caricatura." Revista latinoamericana de estudios sobre la historieta 4.13 (2004): 37-52. Web.

WALKER, NANCY, Y SITA DRESNER. "Women's Humor in America." What's So Funny? Humor in American Culture. Ed. Nancy A. Walker.

Wilmington: Scholarly Resources, ${ }_{1998 .}$ 171 $^{-8} 84$.

Wilcox, Jo H n. Women Poets of Spain, 1860-1990: Toward a Gynocentric Vision. Urbana: U of Illinois P, 1997 . 
$y$ Dios, que era muy hacendosa, prendió la luz y se puso a ordenar...

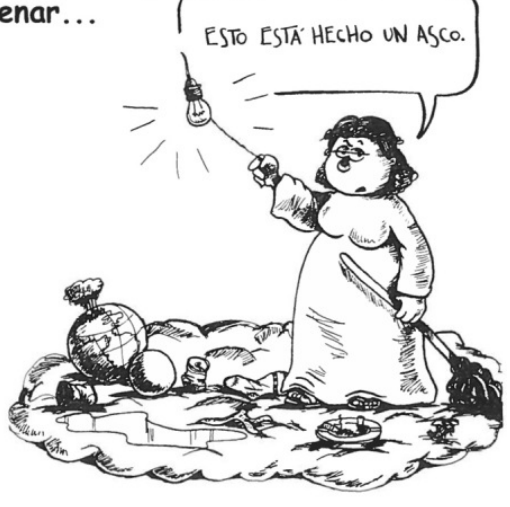

Figura I

Dios quería que fuera su mejor obra, pero le salió de lo más normal...

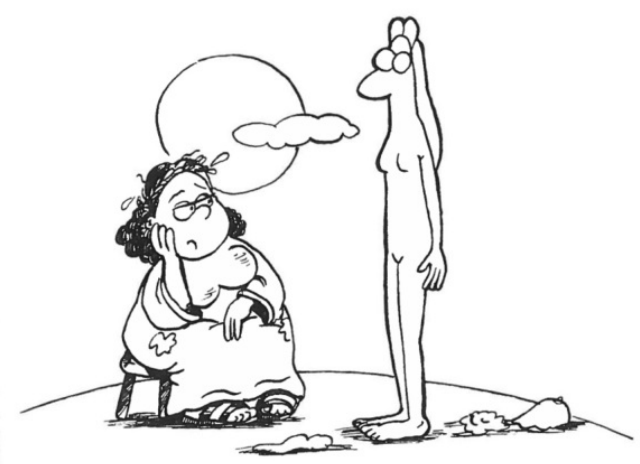

Figura 2 
Para romper el hielo, Dios dijo "creced y multi. plicaos". Y por supuesto Adán hizo mucho caso

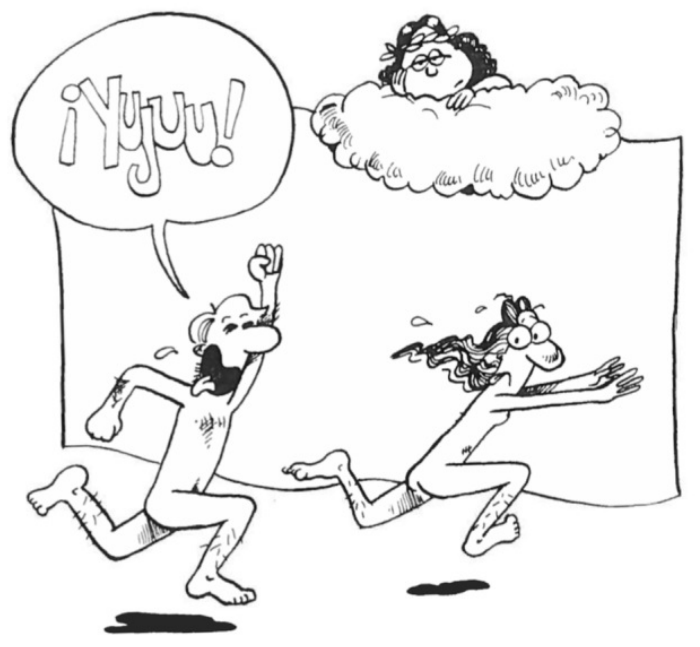

Figura 3

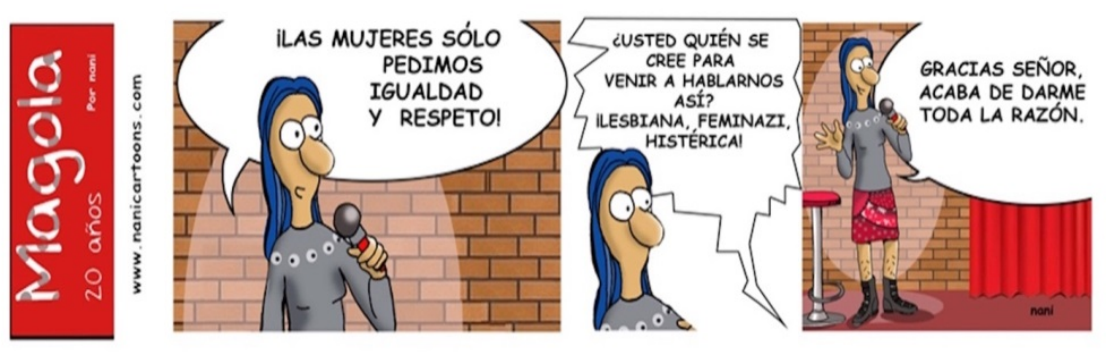

Figura 4 


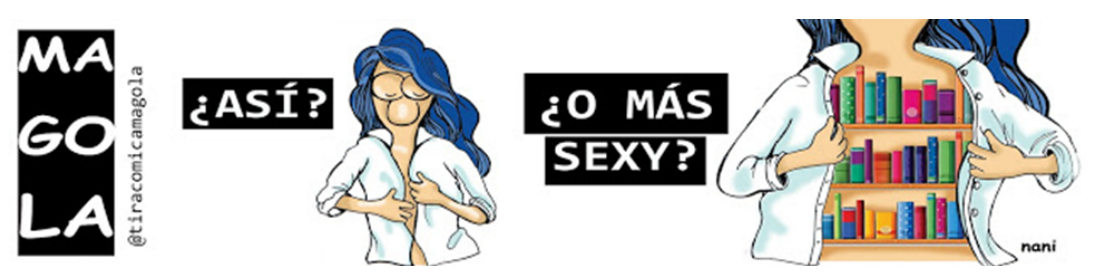

Figura 5

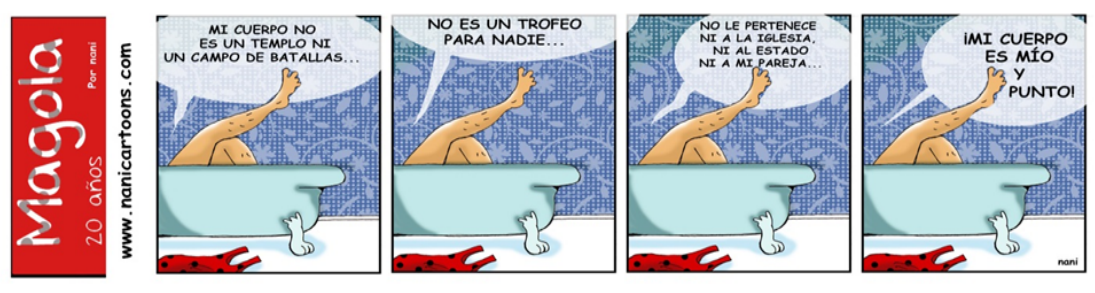

Figura 6 


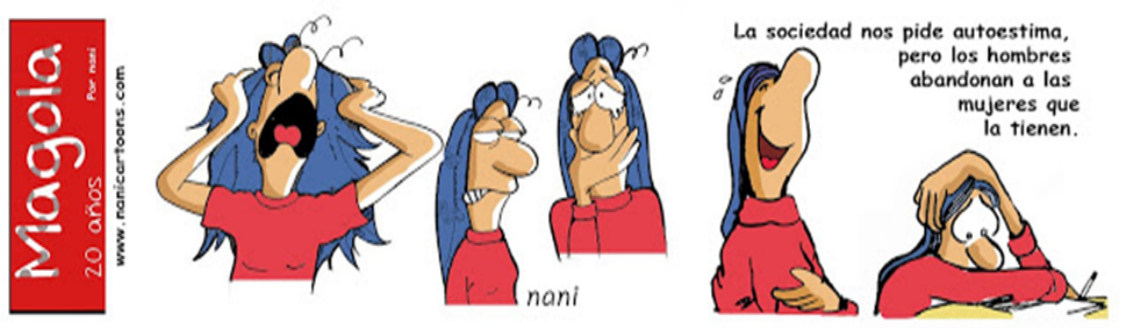

Figura 7

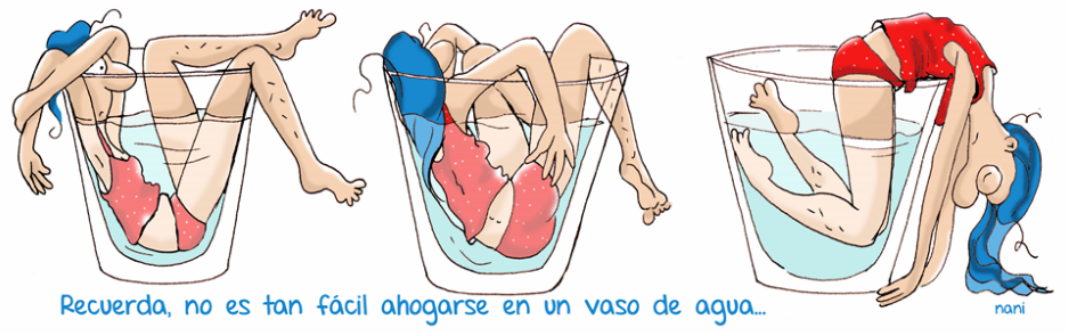

Figura 8 